\title{
Modeling a two-span rotor system based on the Hamilton principle and rotor dynamic behavior analysis
}

\author{
Wei $\mathrm{LI}^{\dagger}$, De-ren SHENG, Jian-hong CHEN, Yong-qiang CHE \\ (Department of Energy Engineering, Zhejiang University, Hangzhou 310027, China) \\ †E-mail: energy@zju.edu.cn
}

Received Apr. 16, 2014; Revision accepted Sept. 15, 2014; Crosschecked Oct. 30, 2014

\begin{abstract}
A nonlinear dynamic model of a two-span rotor system is constructed based on the Hamilton principle and the finite element method. The Musznyska model and the short bearing model are employed to describe the nonlinear seal force and oil-film force. The fourth-order Runge-Kutta method is used to calculate the numerical solutions. The bifurcation diagrams, time-history diagrams, phase trajectories, and Poincare maps are presented to analyze the dynamic behavior of the bearing center and the disk center in the horizontal direction. The numerical results indicate that the rotational speed, the nonlinear seal force, the oil-film force, and the stiffness of the coupling have a significant effect on the stability of the rotor system. The dynamic behavior of the two-span rotor system is more complicated when impacted by the nonlinear seal force and oil-film force.
\end{abstract}

Key words: Hamilton principle, Two-span rotor system, Nonlinear seal force, Dynamic characteristic doi: $10.1631 /$ jzus.A1400100

Document code: A

CLC number: TK14

\section{Introduction}

The field of rotor dynamics is concerned with the research of dynamic and stability characteristics of rotating machinery, and it plays an important role in improving the safety and performance of the entire systems. The modeling of rotor systems and dynamic characteristics analysis are the fundamental research content in the field of rotor dynamics. The rotor system is usually supported by bearings and influenced by internal phenomena that rotor rotates around a single axis. Recently the multi-disk and multi-span rotor system is becoming an important field for rotor dynamics research (Chen, 2009).

Many studies have been conducted on rotor modeling and dynamic characteristics analysis. The Muszynska model highlights the seal force nonlinear

\footnotetext{
" Project supported by the Fundamental Research Funds for the Central Universities (No. 2013QNA4018), China

(C) Zhejiang University and Springer-Verlag Berlin Heidelberg 2014
}

characteristics with clear physical meaning (Muszynska and Bently, 1990). Al-Nahwi et al. (2003) analyzed the principle and interaction of steam excitation on the Jeffcott rotor system combining it with the Moore-Greitzer flow field model. Luo et al. (2007) built a periodical time-variable high-dimensional dynamic rotor system based on the rotor's finite element model and investigated the stability of the system. Cheng et al. (2008) studied the nonlinear dynamic behaviors of a rotor/bearing/seal coupled system with Muszynska's seal forces and Capone's oil-film forces. The influence of the rotation speed, seal clearance, and eccentricity of the rotor were analyzed. de Castro et al. (2008) modeled a flexible rotor with a central disk under unbalanced excitation and validated a complete nonlinear solution to simulate the fluid-induced instability during run-up and run-down. Wang et al. (2009) established a nonlinear mathematical model for orbital motion of the rotor under the influence of leakage flow through an interlocking seal and used the fourth-order RungeKutta method to solve it. Particular attention was 
placed on the serpentine flow path by spatially separating the aerodynamic force on the rotor surface into two parts, e.g., the seal clearance and the cavity volume (Wang et al., 2009). Okabe and Cavalca (2009) developed an analytical model of a tilting pad bearing based on the short bearing assumption with the turbulence effect included. They found that the bearing model with turbulent flow effect generated higher hydrodynamic forces when compared to the one without this effect, which highlights the importance of considering such phenomenon during the analysis of high speed hydrodynamic bearings. Li et al. (2011a; 2011b) applied the Hamilton principle and the finite element method (FEM) to construct a novel nonlinear model of a rotor/bearing/seal system. The dynamic behavior of the system is illustrated by bifurcation diagrams, large Lyapunov exponents, phase trajectory diagrams, and Poincare maps. Li et al. (2012) presented the effects of journal misalignment on the transient flow of a finite grooved journal bearing using a new $3 \mathrm{D}$ computational fluid dynamics analysis method. Based on the FEM and the Lagrange equation, Zhou et al. (2014) proposed a novel nonlinear model of a double disc rotor-seal system, including the coupled effects of the gravity force of the discs, Muszynska's nonlinear seal fluid dynamic force, and the mass eccentricity of the discs. Other researchers focused on the dynamic analysis of rotor systems supported by gas bearings. Půst and Kozánek (2007) calculated the dynamic characteristics of bearings at different revolutions, which took into account the inertia properties of tilting pads. Ertas et al. (2010) tested a rotor system using a 70-mm diameter damped gas bearing reaching ultra-high speeds of $50000 \mathrm{r} / \mathrm{min}$ and experimentally evaluated the ability of the damped gas bearing to withstand large rotor excursions. Rashidi et al. (2010a; 2010b) studied the preload effect on the behavior of a rigid rotor supported by gas-lubricated noncircular journal bearings. Results of this study revealed how the complex dynamic behavior of two types of noncircular bearing systems, comprising periodic, KT-periodic, and quasiperiodic responses of the rotor center, varies with changes in the preload value.

While the above studies were very significant for the rotor design and improvement for academic researches, they simplified the whole rotor/bearing/seal system as a rotor supported by two bearings without taking the concept of multi-rotor into consideration. The simplification of the traditional rotor/bearing/ seal system may lead to some errors in numerical simulation compared with the multi-rotor system, but it would be more difficult to analyze the dynamic orbits of all the geometric centers of rotors.

Recently, the multi-disk and multi-span rotor systems have been the subject of study in the domain of rotor dynamics. Ding and Leung (2005) built a test rotor rig consisting of two flexibly coupled shafts, each supported at the ends by two hydrodynamic bearings. A mathematical model for the test rig was developed and the non-stationary processes of the system were analyzed numerically. $\mathrm{Wu}$ and Jing (2008) established a dynamic model for a two-span bearing-rotor system with nonlinear oil film that was close to a practical situation. The influence of the seal force in the model was not considered. The bifurcation and chaos behaviors of the system under different work conditions were studied. Chang-Jian (2010) investigated the vibration characteristics of two rotors equipped with long journal bearings placed at both ends. Different cross sections, shaft lengths, bearing masses, and different bearing approximations were presented to analyze and discuss the differences of the dynamic responses. Luo et al. (2012) set up a nonlinear dynamic model of a two-span rotor bearing system with two cracks in the shafts and analyzed the characteristics of this system. Fei et al. (2013) discussed a typical structure with two rotor shafts and illustrated the procedure for obtaining the coupling motion equations of the subsystems using the FEM.

In this paper, a dynamic model of a two-disk and two-span rotor/bearing/seal system is created based on the Hamilton principle and the FEM. The rotor system consists of two flexible coupled shafts, each of which is supported by two short journal bearings and attached with one disk. The motion equations of the rotor system were solved with the fourth-order Runge-Kutta method. The nonlinear dynamic behavior of this two-span flexible rotor system was analyzed by the bifurcation diagrams, time-history diagrams, phase trajectories, and Poincare maps. The numerical results indicate that rotational speed, the nonlinear seal force, and the oil-film force have an effect on the stability of the rotor system. 


\section{A nonlinear model of a rotor system based on the Hamilton principle and FEM}

The model of a two-span rotor system supported by four journal bearings is shown in Fig. 1. Two identical Jeffcott rotors are connected with a flexible coupler, each of which is supported by journal bearings on both ends of the rotor. In the following description, the oil-film force model is established by the short bearing theory and the nonlinear seal force is described by the Muszynska model. The expressions of the kinetic energy and strain energy are derived by a projection angle method. In Fig. $1, d$ is the diameter of the shaft, $b_{\mathrm{d}}$ and $d_{\mathrm{d}}$ are the breadth and diameter of the disks, and $L$ and $l_{\mathrm{c}}$ are the length of one span rotor and coupling, respectively.

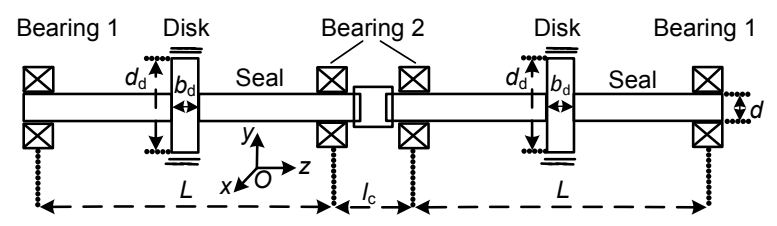

Fig. 1 The physical model of a two-disk and two-span rotor system

\subsection{Nonlinear oil-film force model}

The short bearing unsteady oil-film force model is

$$
\left\{\begin{array}{l}
F_{\mathrm{o} x} \\
F_{\mathrm{o} y}
\end{array}\right\}=\frac{1}{\sigma}\left\{\begin{array}{l}
f_{\mathrm{ox}} \\
f_{\mathrm{o} y}
\end{array}\right\}=\boldsymbol{K}_{\mathrm{o}}\left\{\begin{array}{l}
X \\
Y
\end{array}\right\}-\boldsymbol{C}_{\mathrm{o}}\left\{\begin{array}{c}
\dot{X} \\
\dot{Y}
\end{array}\right\},
$$

where $F_{\mathrm{o} x}$ and $F_{\mathrm{oy}}$ are the bearing oil-film force in the $x$ direction and $y$ direction, respectively; $\sigma=$ $\mu \Omega R_{\mathrm{o}} L_{\mathrm{o}}\left(\frac{R_{\mathrm{o}}}{c_{\mathrm{o}}}\right)^{2}\left(\frac{L_{\mathrm{o}}}{2 R_{\mathrm{o}}}\right)^{2}$ is the Sommerfeld coefficient, $\mu$ is the sectional shear correction factor, $\Omega$ is the rotational speed of the rotor, $X=x / c_{\mathrm{o}}$ and $Y=y / c_{\mathrm{o}}$ are defined as the dimensionless translation displacements at the bearing, $c_{\mathrm{o}}, R_{\mathrm{o}}$, and $L_{\mathrm{o}}$ are the average clearance, radius, and length of the bearing, respectively. $\dot{X}=\frac{\partial X}{\partial \tau}=\frac{\dot{x}}{\Omega c_{0}}, \quad \dot{Y}=\frac{\partial Y}{\partial \tau}=\frac{\dot{y}}{\Omega c_{0}}, \tau=\Omega t$ is dimensionless time. $\boldsymbol{K}_{\mathrm{o}}$ and $\boldsymbol{C}_{\mathrm{o}}$ can be written as

$$
\boldsymbol{K}_{\mathrm{o}}=\frac{1}{2}\left[\begin{array}{cc}
C_{2} & -C_{3} \\
C_{3} & C_{2}
\end{array}\right], \boldsymbol{C}_{\mathrm{o}}=\left[\begin{array}{ll}
C_{11} & C_{12} \\
C_{21} & C_{22}
\end{array}\right],
$$

where

$C_{11}=C_{1} \cos ^{2} \varphi+C_{3} \sin ^{2} \varphi-2 C_{2} \sin \varphi \cos \varphi$,

$C_{12}=C_{21}=C_{2}\left(\cos ^{2} \varphi-\sin ^{2} \varphi\right)+\left(C_{1}-C_{3}\right) \sin \varphi \cos \varphi$,

$C_{22}=C_{1} \sin ^{2} \varphi+C_{3} \cos ^{2} \varphi+2 C_{2} \sin \varphi \cos \varphi$,

$C_{1}=\frac{4 \varepsilon \dot{\varepsilon} A_{0}\left[3 A_{0}^{2}+\left(2-5 \varepsilon^{2}\right) \varepsilon^{2}(\dot{\Phi}-1 / 2)^{2}\right]}{\left(1+\varepsilon^{2}\right)^{2}\left[A_{0}^{2}-\varepsilon^{4}(\dot{\Phi}-1 / 2)^{2}\right]^{2}}+\frac{2+4 \varepsilon^{2}}{\left(1-\varepsilon^{2}\right)^{5 / 2}} \Delta \varphi$,

$C_{2}=\frac{8 A_{\mathrm{o}} \varepsilon^{4}(\dot{\Phi}-1 / 2)^{3}}{\left[A_{\mathrm{o}}^{2}-\varepsilon^{4}(\dot{\Phi}-1 / 2)^{2}\right]^{2}}$,

$C_{3}=\frac{4 \varepsilon \dot{\varepsilon} A_{0}\left[A_{0}^{2}+\left(\varepsilon^{2}-2\right) \varepsilon^{2}(\dot{\Phi}-1 / 2)^{2}\right]}{\left(1+\varepsilon^{2}\right)\left[A_{0}^{2}-\varepsilon^{4}(\dot{\Phi}-1 / 2)^{2}\right]^{2}}+\frac{2}{\left(1-\varepsilon^{2}\right)^{3 / 2}} \Delta \varphi$,

$A_{\mathrm{o}}=\sqrt{\dot{\varepsilon}^{2}+(\dot{\Phi}-1 / 2) \varepsilon^{2}}$,

$\Delta \varphi=\pi+2 \arctan \left(\frac{\varepsilon \dot{\varepsilon}}{A_{\mathrm{o}} \sqrt{1-\varepsilon^{2}}}\right)$,

$\varepsilon=\sqrt{X^{2}+Y^{2}}$,

$\dot{\Phi}=\frac{X \dot{X}+Y \dot{Y}}{\varepsilon^{2}}$.

\subsection{Nonlinear seal force model}

The Muszynska model can be used to describe the nonlinear characteristic of a steam excitation force very well. The expression of this model can be described as follows (Muszynska and Bently, 1990):

$$
\begin{aligned}
& \left\{\begin{array}{l}
F_{\mathrm{sx}} \\
F_{\mathrm{s} y}
\end{array}\right\}=-c_{\mathrm{o}}\left[\begin{array}{cc}
K_{\mathrm{f}}-m_{\mathrm{f}} \tau_{\mathrm{f}}^{2} \Omega^{2} & \tau_{\mathrm{f}} \Omega D_{\mathrm{f}} \\
-\tau_{\mathrm{f}} \Omega D_{\mathrm{f}} & K_{\mathrm{f}}-m_{\mathrm{f}} \tau_{\mathrm{f}}^{2} \Omega^{2}
\end{array}\right]\left\{\begin{array}{l}
X \\
Y
\end{array}\right\} \\
& -\Omega c_{\mathrm{o}}\left[\begin{array}{cc}
D_{\mathrm{f}} & 2 \tau \Omega m_{\mathrm{f}} \\
2 \tau \Omega m_{\mathrm{f}} & D_{\mathrm{f}}
\end{array}\right]\left\{\begin{array}{l}
\dot{X} \\
\dot{Y}
\end{array}\right\}-\Omega^{2} c_{\mathrm{o}}\left[\begin{array}{cc}
m_{\mathrm{f}} & 0 \\
0 & m_{\mathrm{f}}
\end{array}\right]\left\{\begin{array}{l}
\ddot{X} \\
\ddot{Y}
\end{array}\right\},
\end{aligned}
$$

where $F_{\mathrm{s} x}$ and $F_{\mathrm{s} y}$ are the seal force in the $x$ direction and $y$ direction, respectively; $K_{\mathrm{f}}, D_{\mathrm{f}}$, and $\tau_{\mathrm{f}}$ are the nonlinear functions of the translation displacements $x$ and $y$ at the disk. They can be written as

$$
\begin{gathered}
K_{\mathrm{f}}=K_{\mathrm{o}}\left(1-\mathrm{e}^{2}\right)^{-n}, D_{\mathrm{f}}=D_{\mathrm{o}}\left(1-\mathrm{e}^{2}\right)^{-n}, \quad 0.5 \leq n \leq 3, \\
\tau_{\mathrm{f}}=\tau_{\mathrm{o}}(1-\mathrm{e})^{b}, \quad 0<b<1, \tau_{\mathrm{o}}<0.5,
\end{gathered}
$$

where $K_{\mathrm{o}}, D_{\mathrm{o}}$, and $m_{\mathrm{f}}$ can be obtained from the Childs equation (Childs, 1983). 


\subsection{Finite element model of a rotor system}

The finite element model of a rotor system is established by applying the FEM as Fig. 2, where $m_{\mathrm{d}}$ is the disk mass. There are six nodes in total, which are distributed on the bearings, disks, and five shaft elements. The displacement vector of the shaft element between nodes 1 and 2 can be written as

$$
\boldsymbol{q}_{\mathrm{e} 12}=\left[\begin{array}{llllllll}
x_{1} & y_{1} & \theta_{x 1} & \theta_{y 1} & x_{2} & y_{2} & \theta_{x 2} & \theta_{y 2}
\end{array}\right]^{\mathrm{T}} .
$$

The translation displacements and rotation displacements of a random point in the shaft element can be approximated as

$$
\begin{aligned}
& \left\{\begin{array}{l}
x \\
y
\end{array}\right\}=\boldsymbol{N} \boldsymbol{q}_{\mathrm{e}}=\left[\begin{array}{cccccccc}
N_{1} & 0 & 0 & N_{2} & N_{3} & 0 & 0 & N_{4} \\
0 & N_{1} & -N_{2} & 0 & 0 & N_{3} & -N_{4} & 0
\end{array}\right] \boldsymbol{q}_{\mathrm{e}}, \\
& \left\{\begin{array}{l}
\theta_{x} \\
\theta_{y}
\end{array}\right\}=\boldsymbol{D} \boldsymbol{q}_{\mathrm{e}}=\left[\begin{array}{cccccccc}
0 & -D_{1} & D_{2} & 0 & 0 & -D_{3} & D_{4} & 0 \\
D_{1} & 0 & 0 & D_{2} & D_{3} & 0 & 0 & D_{4}
\end{array}\right] \boldsymbol{q}_{\mathrm{e}},
\end{aligned}
$$

where $\boldsymbol{D}$ is the rotation displacement shape function matrix, and $N$ is the translation displacement shape function matrix. The expressions of $N_{i}$ and $D_{i}(i=1,2$, $3,4)$ can be found in (Zeng, 2004).

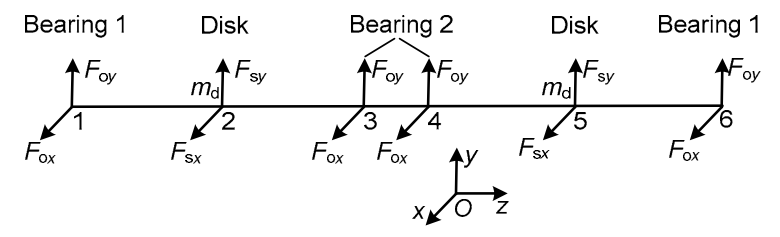

Fig. 2 The finite element model of a rotor system

\subsection{Hamilton principle}

A general dynamic problem with $N$ degrees of freedom should be expressed by $N$ differential equations. By using the Hamilton principle, there is only one equation. This means that the Hamilton principle is highly recapitulative for dynamics problems and independent of the choice of coordinate systems, while the Newton equation changes along with the coordinate systems. Therefore, the Hamilton principle is more convenient to use for analyzing the dynamic systems.

The extended Hamilton principle can be expressed as

$$
\int_{t_{0}}^{t_{1}}(\delta T-\delta U+\delta W) \mathrm{d} t=0
$$

where $T$ and $U$ are kinetic energy and potential energy of the rotor system, respectively, and $W$ is the work done by non-conservative forces and any forces not accounted for in the potential energy function.

The kinetic energy of the shaft element $\left(T_{\mathrm{s}}\right)$ and the disk $\left(T_{\mathrm{d}}\right)$ under the fixed coordinate system can be written as

$$
\begin{aligned}
T_{\mathrm{s}}= & \int_{0}^{l} \frac{1}{2} \rho\left\{A\left(\dot{x}^{2}+\dot{y}^{2}\right)+I_{\mathrm{d}}\left(\dot{\theta}_{x}^{2}+\dot{\theta}_{y}^{2}\right)\right. \\
& \left.+I_{\mathrm{p}}\left[\Omega^{2}+\Omega\left(\dot{\theta}_{x} \theta_{y}-\dot{\theta}_{y} \theta_{x}\right)\right]\right\} \mathrm{d} s, \\
T_{\mathrm{d}}= & \int_{0}^{l} \frac{1}{2} m_{\mathrm{d}}\left(\dot{x}^{2}+\dot{y}^{2}\right)+\frac{1}{2} J_{\mathrm{d}}\left(\dot{\theta}_{x}^{2}+\dot{\theta}_{y}^{2}\right) \\
& +\frac{1}{2} J_{\mathrm{p}}\left[\Omega^{2}+\Omega\left(\dot{\theta}_{x} \theta_{y}-\dot{\theta}_{y} \theta_{x}\right)\right],
\end{aligned}
$$

where $l$ is the length of the shaft element; $\rho$ is the material density of shaft unit; $I_{\mathrm{d}}$ and $I_{\mathrm{p}}$ are the diametric inertia moment and polar inertia moment of the shaft element, respectively; and $J_{\mathrm{d}}$ and $J_{\mathrm{p}}$ are the diametric inertia moment and polar inertia moment of the disk, respectively.

Considering the bending and shearing distortion of the shaft element, the strain energy of the shaft element can be obtained as

$$
\begin{aligned}
U_{\mathrm{s}}= & \int_{0}^{l} \frac{1}{2}\left\{E I\left[\left(\theta_{x}^{\prime}\right)^{2}+\left(\theta_{y}^{\prime}\right)^{2}\right]\right. \\
& \left.+k G A\left[\left(\theta_{y}-x^{\prime}\right)^{2}+\left(\theta_{x}+y^{\prime}\right)^{2}\right]\right\} \mathrm{d} s,
\end{aligned}
$$

where $E$ is the Young's modulus of elasticity, $I$ is the area rotary inertia of shaft unit, $k$ is the shape factor, $G$ is the gravity vector of the rotor system, $A$ is the sectional area of shaft unit, $x^{\prime}=\frac{\partial x}{\partial s}, y^{\prime}=\frac{\partial y}{\partial s}, \theta_{x}^{\prime}=\frac{\partial \theta_{x}}{\partial s}$, and $\theta_{y}^{\prime}=\frac{\partial \theta_{y}}{\partial s}$.

By substituting Eqs. (6) and (7) into Eqs. (9) and (11), the following energy equation of the shaft element can be obtained:

$$
T_{\mathrm{e}}=\frac{1}{2} \dot{\boldsymbol{q}}_{\mathrm{e}}^{\mathrm{T}} \boldsymbol{M}_{\mathrm{e}} \dot{\boldsymbol{q}}_{\mathrm{e}}+\frac{1}{2} \rho l I_{\mathrm{p}} \Omega^{2}+\frac{1}{2} \Omega \dot{\boldsymbol{q}}_{\mathrm{e}}^{\mathrm{T}} \boldsymbol{\Omega}_{\mathrm{e}} \boldsymbol{q}_{\mathrm{e}},
$$




$$
U_{\mathrm{e}}=\frac{1}{2} \boldsymbol{q}_{\mathrm{e}}^{\mathrm{T}} \boldsymbol{K}_{\mathrm{e}} \boldsymbol{q}_{\mathrm{e}}
$$

where

$$
\begin{gathered}
\boldsymbol{M}_{\mathrm{e}}=\int_{0}^{l} \rho A \boldsymbol{N}^{\mathrm{T}} \boldsymbol{N} \mathrm{d} s+\int_{0}^{l} \rho I_{\mathrm{d}} \boldsymbol{D}^{\mathrm{T}} \boldsymbol{D} \mathrm{d} s, \\
\boldsymbol{\Omega}_{\mathrm{e}}=\int_{0}^{l} \rho I_{\mathrm{p}} \boldsymbol{D}^{\mathrm{T}}\left[\begin{array}{cc}
0 & 1 \\
-1 & 0
\end{array}\right] \boldsymbol{D} \mathrm{d} s
\end{gathered}
$$$$
\text { and }
$$

are the mass matrix and the gyroscope matrix of the shaft element, respectively;

$$
\begin{aligned}
\boldsymbol{K}_{\mathrm{e}}= & \int_{0}^{l} E I \boldsymbol{D}^{\prime \mathrm{T}} \boldsymbol{D}^{\prime} \mathrm{d} s \\
& +\int_{0}^{l} k G A\left\{\boldsymbol{N}^{\prime \mathrm{T}} \boldsymbol{N}^{\prime}+\boldsymbol{D}^{\mathrm{T}} \boldsymbol{D}+2 \boldsymbol{N}^{\prime \mathrm{T}}\left[\begin{array}{cc}
0 & -1 \\
1 & 0
\end{array}\right] \boldsymbol{D}\right\} \mathrm{d} s
\end{aligned}
$$

is the stiffness matrix of the shaft element.

\subsection{Motion equation}

The shaft element motion equation can be achieved by substituting Eqs. (12) and (13) into Eq. (8) as follows:

$$
\begin{gathered}
\boldsymbol{M}_{\mathrm{e}} \ddot{\boldsymbol{q}}_{\mathrm{e}}+\left(\Omega \boldsymbol{\Omega}_{\mathrm{e}}+\boldsymbol{C}_{\mathrm{e}}\right) \dot{\boldsymbol{q}}_{\mathrm{e}}+\boldsymbol{K}_{\mathrm{e}} \boldsymbol{q}_{\mathrm{e}}=\boldsymbol{F}_{\mathrm{e}}+\boldsymbol{G}_{\mathrm{e}}, \\
\boldsymbol{M}_{\mathrm{d}} \ddot{\boldsymbol{q}}_{\mathrm{d}}+\left(\Omega \boldsymbol{\Omega}_{\mathrm{d}}+\boldsymbol{C}_{\mathrm{d}}\right) \dot{\boldsymbol{q}}_{\mathrm{d}}=\boldsymbol{F}_{\mathrm{d}}+\boldsymbol{G}_{\mathrm{d}},
\end{gathered}
$$

where

$$
\boldsymbol{M}_{\mathrm{d}}=\left[\begin{array}{cccc}
m_{\mathrm{d}} & & & \\
& m_{\mathrm{d}} & & \\
& & J_{\mathrm{d}} & \\
& & & J_{\mathrm{d}}
\end{array}\right], \boldsymbol{\Omega}_{\mathrm{d}}=\left[\begin{array}{cccc}
0 & & & \\
& 0 & & \\
& 0 & J_{\mathrm{p}} \\
& & -J_{\mathrm{p}} & 0
\end{array}\right] ;
$$

$\boldsymbol{C}_{\mathrm{e}}$ and $\boldsymbol{C}_{\mathrm{d}}$ are the damping matrixes of shaft unit and disk, respectively; $\boldsymbol{F}_{\mathrm{e}}$ and $\boldsymbol{F}_{\mathrm{d}}$ are the vectors of forces acting on shaft unit and disk, respectively; and $\boldsymbol{G}_{\mathrm{e}}$ and $\boldsymbol{G}_{\mathrm{d}}$ are the gravity vectors of the shaft unit and disk, respectively.

The motion equation of the rotor system can be achieved by assembling all the shaft elements and the disks while ignoring the rotation displacement, which is given as follows:

$$
\boldsymbol{M} \ddot{\boldsymbol{q}}+(\Omega \Omega+\boldsymbol{C}) \dot{\boldsymbol{q}}+\boldsymbol{K} \boldsymbol{q}=\boldsymbol{F}+\boldsymbol{G},
$$

where $\boldsymbol{q}=\left[\begin{array}{lllllll}x_{1} & y_{1} & x_{2} & y_{2} & \ldots & x_{12} & y_{12}\end{array}\right]^{\mathrm{T}}$ is the nodal displacement vector of the rotor system, $\boldsymbol{K}$ is the stiffness matrix of the rotor system, $\boldsymbol{G}$ is the gravity vector of the rotor system, and

$$
\begin{aligned}
& \boldsymbol{F}=\left[\begin{array}{lllllll}
F_{\mathrm{o} x} & F_{\mathrm{o} y} & F_{\mathrm{s} x}+F_{\mathrm{d} x} & F_{\mathrm{s} y}+F_{\mathrm{d} y} & F_{\mathrm{o} x} & F_{\mathrm{o} y} & F_{\mathrm{o} x}
\end{array}\right.
\end{aligned}
$$

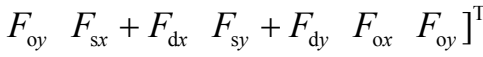

is the vector of the forces acting on the rotor system, where $F_{\mathrm{d} x}=m_{\mathrm{d}} r_{\mathrm{d}} \Omega^{2} \cos (\Omega t)$ and $F_{\mathrm{d} y}=m_{\mathrm{d}} r_{\mathrm{d}} \Omega^{2} \sin (\Omega t)$ are the eccentric force acting on the disk in the $x$ and $y$ directions, respectively.

We can define the dimensionless time and dimensionless displacement as follows:

$$
\boldsymbol{Q}=\boldsymbol{q} / \mathcal{c}_{0}=\left[\begin{array}{llllllllll}
X_{1} & Y_{1} & X_{2} & Y_{2} & X_{3} & Y_{3} & X_{4} & Y_{4} & X_{5} & Y_{5}
\end{array}\right]^{\mathrm{T}} .
$$

Therefore, Eq. (16) can be transformed as

$$
\Omega^{2} c_{\mathrm{o}} \boldsymbol{M} \ddot{\boldsymbol{Q}}+\Omega c_{\mathrm{o}}(\Omega \boldsymbol{\Omega}+\boldsymbol{C}) \dot{\boldsymbol{Q}}+c_{\mathrm{o}} \boldsymbol{K} \boldsymbol{Q}=\boldsymbol{F}+\boldsymbol{G}
$$

\section{Numerical analysis and discussion}

In this study, time-history diagrams, bifurcation diagrams, phase trajectory diagrams, and Poincare maps are used to illustrate the nonlinear dynamics of the rotor system. In the dynamic system, a bifurcation diagram shows the possible long-term values (equilibria/fixed points or periodic orbits) of a system as a function of a bifurcation parameter in the system. A Poincare map can be interpreted as a discrete dynamical system with a state space that is one dimension smaller than the original continuous dynamical system. By numerical integration of the equations of the rotor motion, the $y$ coordinate, which denotes the dimensionless speed in the $x$ or $y$ direction, can be plotted versus the $x$ coordinate, which stands for the dimensionless displacement in the $x$ or $y$ direction as the time increases. This produces a phase trajectory diagram.

The numerical analysis was performed by using the fourth-order Runge-Kutta method and implemented in MATLAB. The main partial parameters of the numerical calculation are listed in Table 1. The bifurcation diagrams at bearings and disks are plotted as shown in Fig. 3. Trajectory diagrams, time-history diagrams, and Poincare maps of disks and bearings at different rotational speeds are also listed to analyze 
the dynamic characteristics of the rotor system in this study. For simplicity, all the diagrams are only illustrated in the $x$ direction. In the numerical calculation, the structural damping of the bearing is $2300 \mathrm{~N} \cdot \mathrm{s} / \mathrm{m}$, and the disk's is $5300 \mathrm{~N} \cdot \mathrm{s} / \mathrm{m}$. These dampings are described as vectors and added to the material damping of the rotor system. The stiffness of the flexible coupler is very small, which can be deemed as $1 / 100$ of its nearby shaft element. The dimensionless time ranges from 0 to $800 \pi$, and the step is $0.01 \pi$. Thus, 80001 data can be achieved. The latter 40001 data are plotted, while the first 40000 data are omitted considering the iteration veracity. In addition, the seal length, seal pressure drop, structural damping, and the stiffness of the rotor system are varied for the dynamic characteristic analysis of the rotor system's stability.

Table 1 Partial test parameters

\begin{tabular}{cc||cc}
\hline $\begin{array}{c}\text { Structural } \\
\text { parameter }\end{array}$ & Value & $\begin{array}{c}\text { Characteristic } \\
\text { parameter }\end{array}$ & Value \\
\hline$L(\mathrm{~m})$ & 1 & $\rho\left(\mathrm{kg} / \mathrm{m}^{3}\right)$ & 7810 \\
$l(\mathrm{~m})$ & 0.5 & $E(\mathrm{MPa})$ & $1.97 \times 10^{5}$ \\
$d(\mathrm{~m})$ & 0.05 & $G(\mathrm{MPa})$ & $8.0 \times 10^{4}$ \\
$d_{\mathrm{d}}(\mathrm{m})$ & 0.5 & $k$ & 0.65 \\
$l_{\mathrm{s}}(\mathrm{m})$ & 0.052 & $n$ & 2.5 \\
$r_{\mathrm{d}}(\mathrm{mm})$ & 0.06 & $b$ & 0.45 \\
$c_{\mathrm{o}}(\mathrm{mm})$ & 0.2 & $\tau_{\mathrm{o}}$ & 0.2 \\
$L_{\mathrm{o}}(\mathrm{mm})$ & 25.2 & $\Delta p(\mathrm{MPa})$ & 0.2 \\
$R_{\mathrm{o}}(\mathrm{mm})$ & 25.2 & & \\
$c_{\mathrm{s}}(\mathrm{mm})$ & 1 & & \\
$l_{\mathrm{c}}(\mathrm{m})$ & 0.2 & & \\
\hline
\end{tabular}

Fig. 3 shows the bifurcation diagrams at bearing 1, bearing 2, and the disks. Figs. 4-8 illustrate the time-history diagrams, the trajectory diagrams, and the Poincare maps with different rotational speeds at bearing 1, bearing 2, and the disks. In Fig. 3, it can be determined that at a lower speed, $\Omega \leq 700 \mathrm{rad} / \mathrm{s}$, the system motion is maintained steady, which is a periodic motion and the amplitude is limited. When $\Omega>700 \mathrm{rad} / \mathrm{s}$, the system turns into a triple periodic motion, which is shown as three isolated points in the corresponding Poincare map and three obvious frequency parts in the frequency spectrum. The trajectory diagram also reflects this characteristic. Meanwhile, the amplitude is greatly increased. When the rotational speed increases to $720-760 \mathrm{rad} / \mathrm{s}$, the rotor system represents quasi-periodic motion, which is shown as a whole cycle in the Poincare map. The motion of the system becomes triple periodic motion in the range of $764 \mathrm{rad} / \mathrm{s} \leq \Omega \leq 792 \mathrm{rad} / \mathrm{s}$. With increasing rotational speed, the response of the rotor system becomes more complicated, and the quasiperiodic motion and multi-periodic motion happen alternatively. For example, the quasi-periodic motion
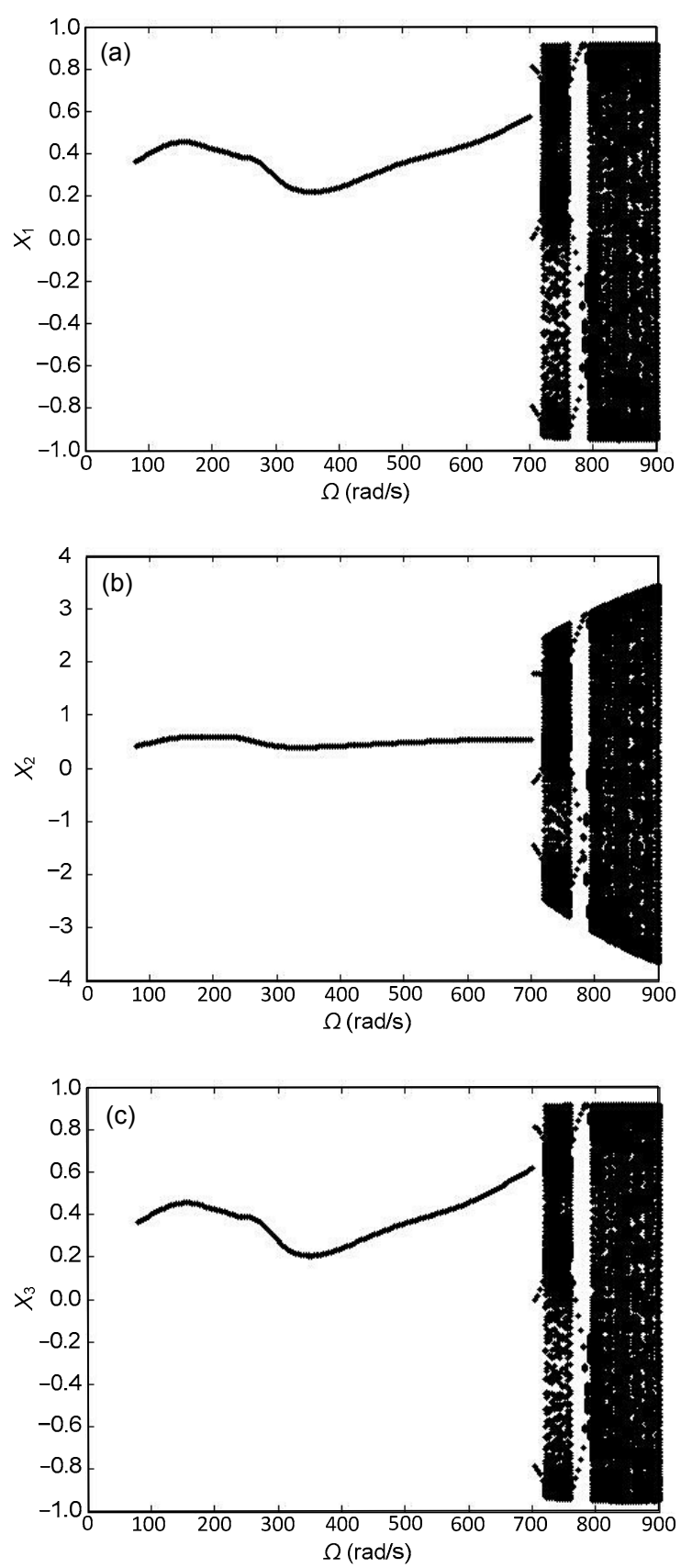

Fig. 3 Bifurcation diagram at bearing 1 (a), disk (b), and bearing 2 (c) with rotational speed increasing 

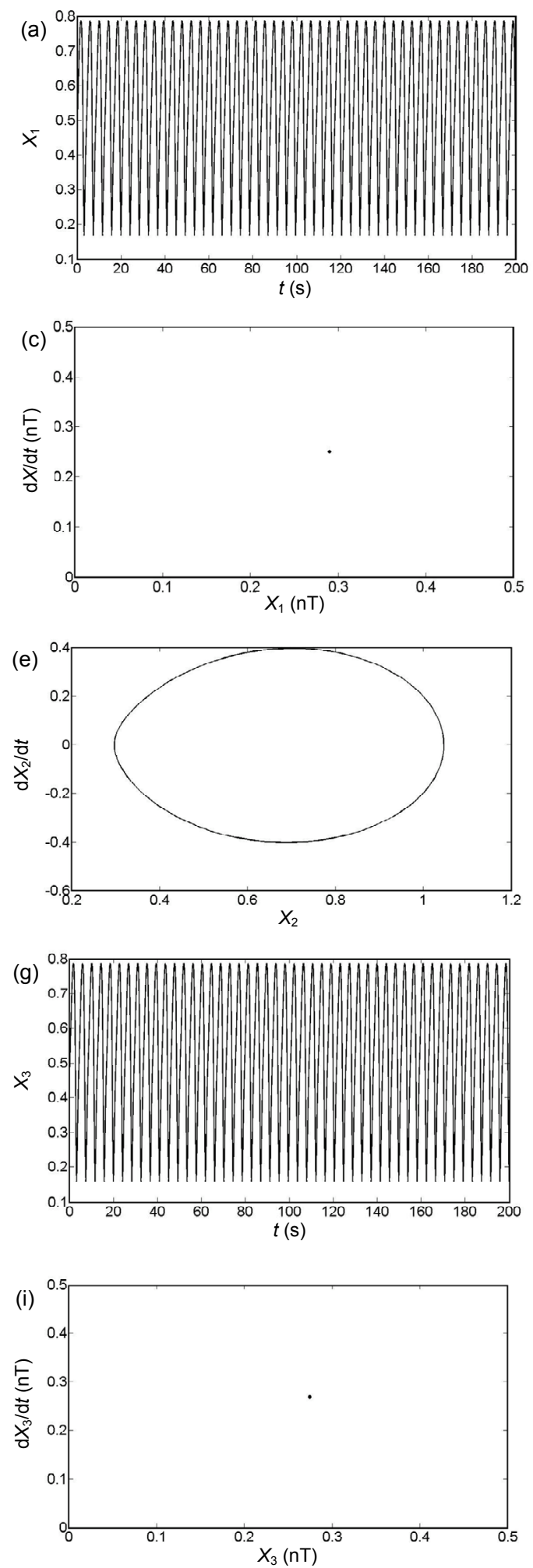
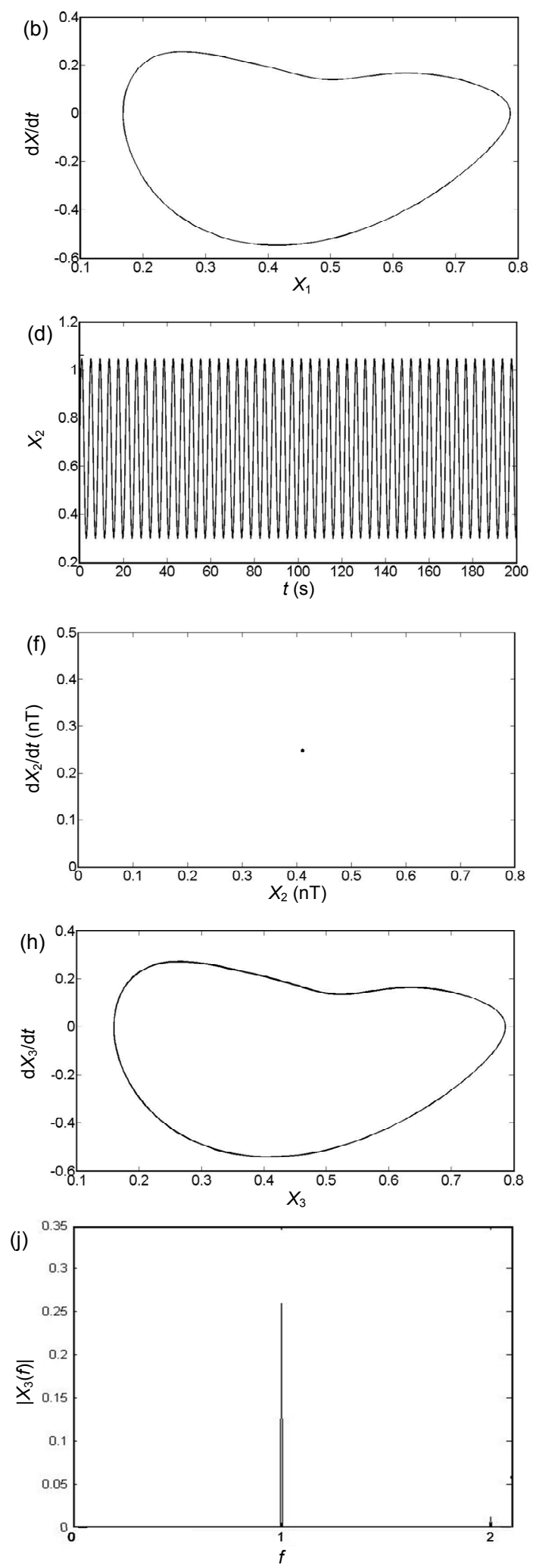

Fig. 4 Numerical analysis results at $\Omega=300 \mathrm{rad} / \mathrm{s}$

(a) Time-history diagram at bearing 1; (b) Trajectory diagram at bearing 1; (c) Poincare map at bearing 1; (d) Time-history diagram at the disk; (e) Trajectory diagram at the disk; (f) Poincare map at the disk; (g) Time-history diagram at bearing 2; (h) Trajectory diagram at bearing 2; (i) Poincare map at bearing 2; (j) Frequency spectrum at bearing 2 
(a)
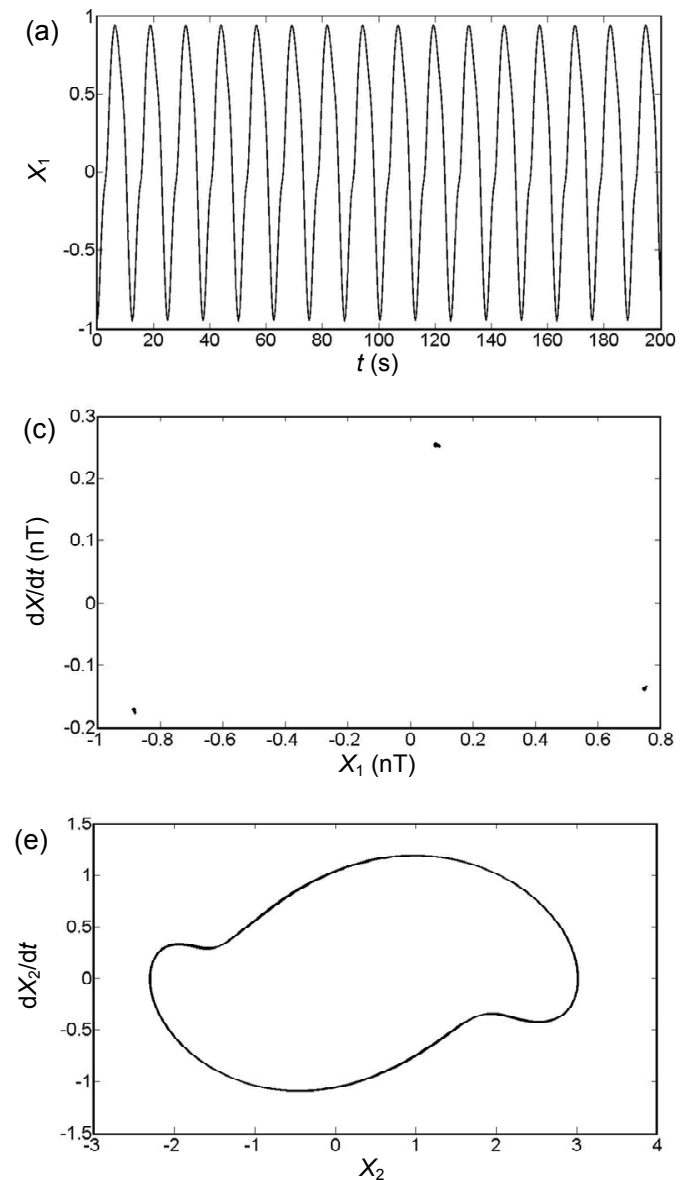

(g)
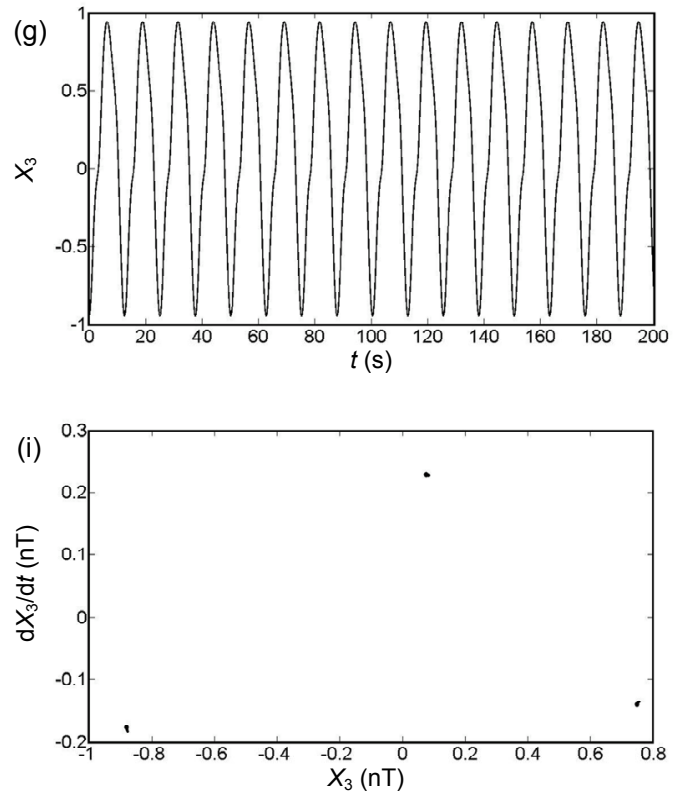

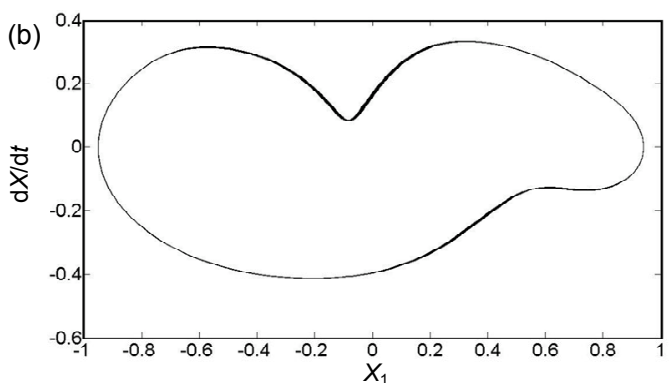

(d)
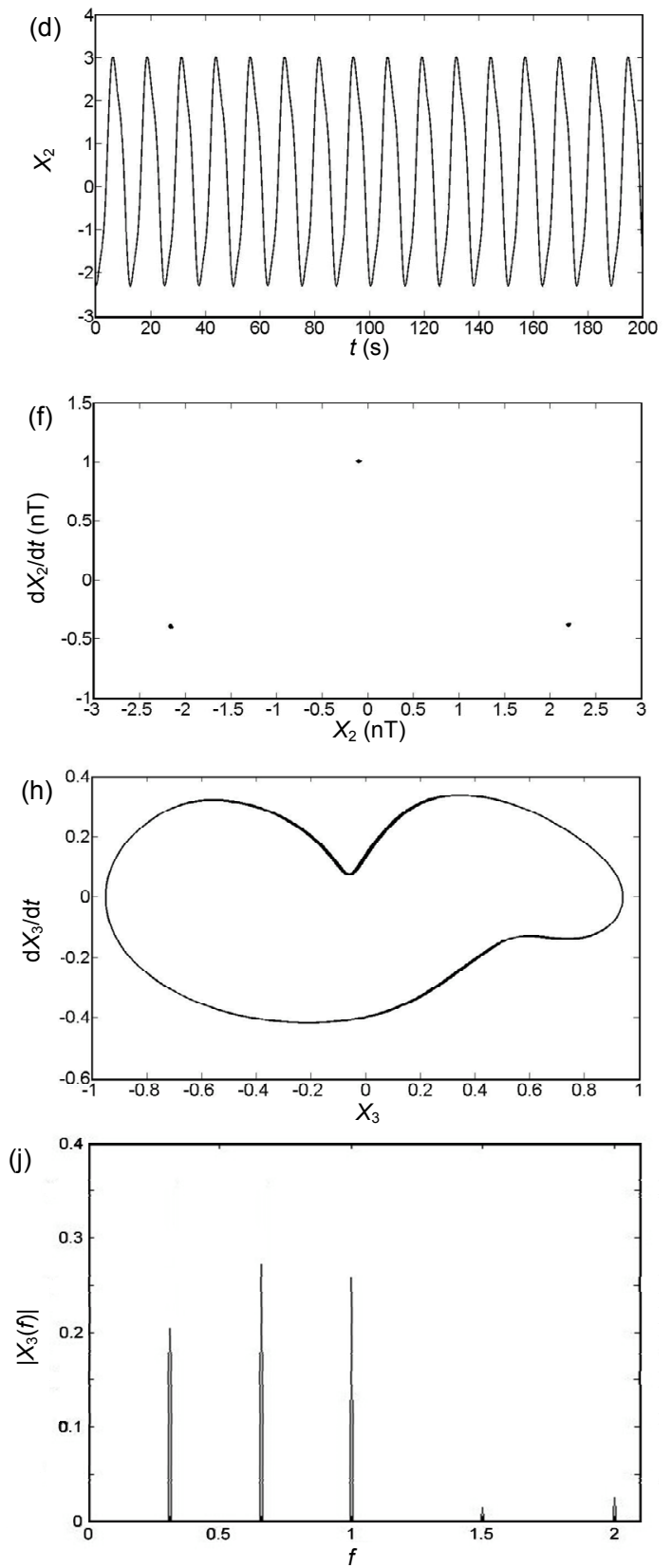

Fig. 5 Numerical analysis results at $\Omega=764 \mathrm{rad} / \mathrm{s}$

(a) Time-history diagram at bearing 1; (b) Trajectory diagram at bearing 1; (c) Poincare map at bearing 1; (d) Time-history diagram at the disk; (e) Trajectory diagram at the disk; (f) Poincare map at the disk; (g) Time-history diagram at bearing 2; (h) Trajectory diagram at bearing 2; (i) Poincare map at bearing 2; (j) Frequency spectrum at bearing 2 
(a)
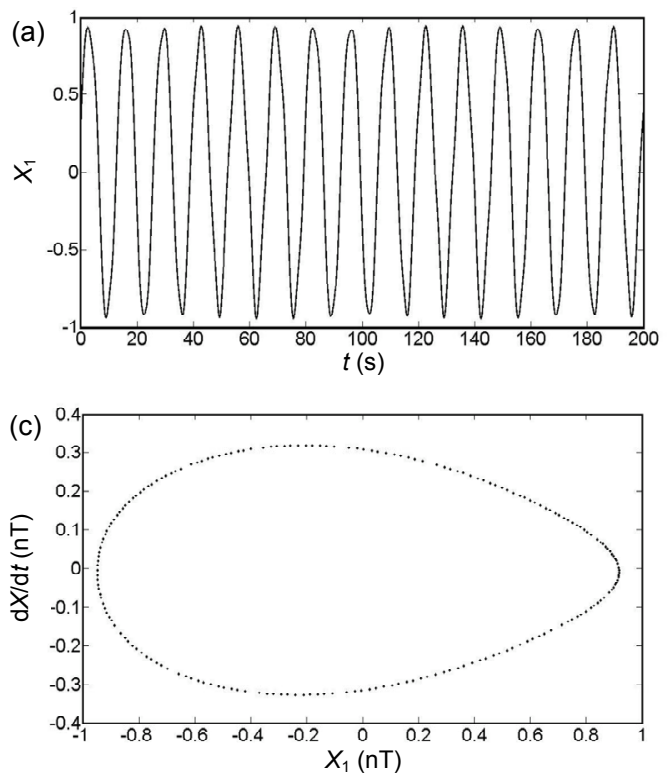

(e)
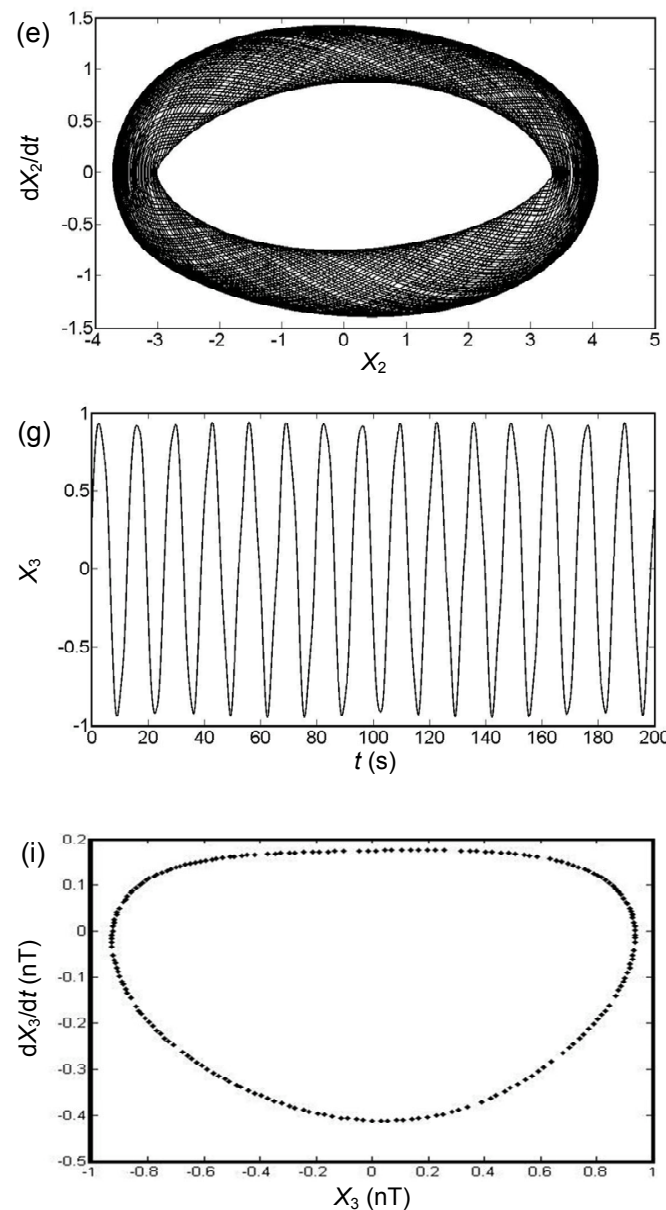
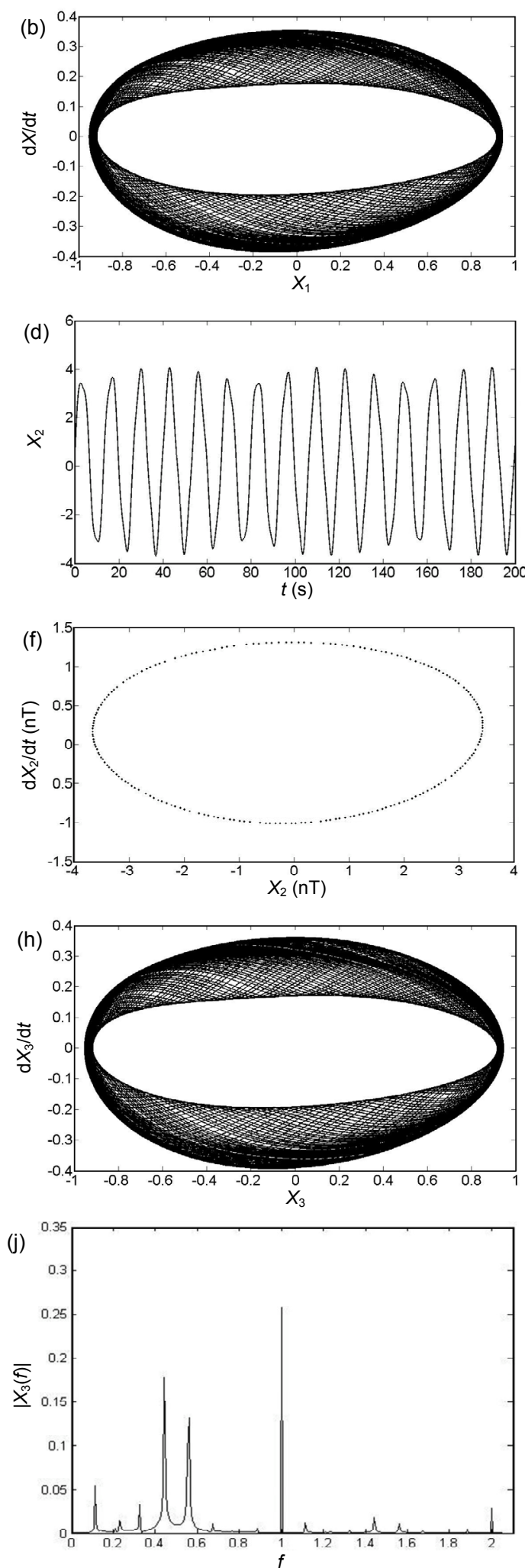

Fig. 6 Numerical analysis results at $\Omega=900 \mathrm{rad} / \mathrm{s}$

(a) Time-history diagram at bearing 1; (b) Trajectory diagram at bearing 1; (c) Poincare map at bearing 1; (d) Time-history diagram at the disk; (e) Trajectory diagram at the disk; (f) Poincare map at the disk; (g) Time-history diagram at bearing 2; (h) Trajectory diagram at bearing 2; (i) Poincare map at bearing 2; (j) Frequency spectrum at bearing 2 
(a)
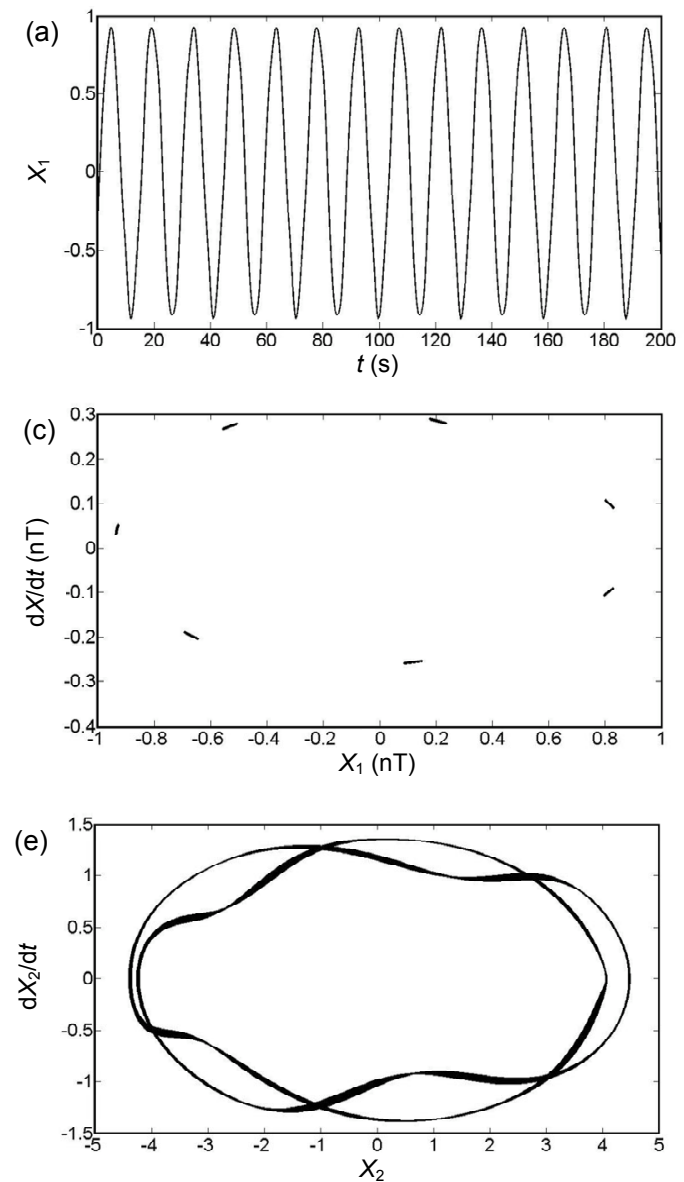

(g)
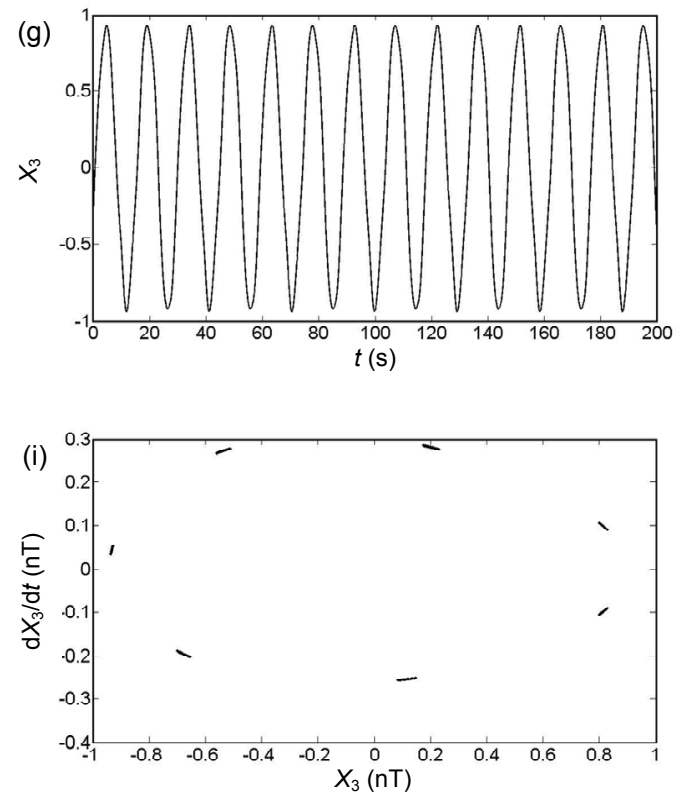
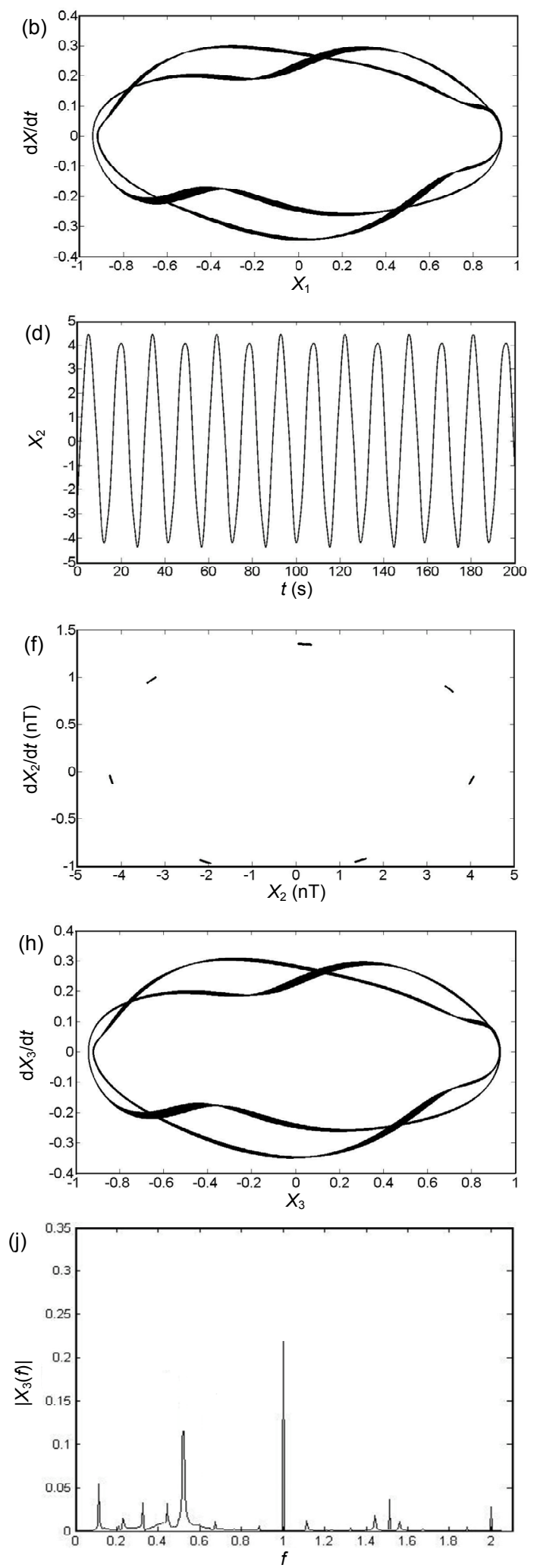

Fig. 7 Numerical analysis results at $\Omega=1216 \mathrm{rad} / \mathrm{s}$

(a) Time-history diagram at bearing 1; (b) Trajectory diagram at bearing 1; (c) Poincare map at bearing 1; (d) Time-history diagram at the disk; (e) Trajectory diagram at the disk; (f) Poincare map at the disk; (g) Time-history diagram at bearing 2; (h) Trajectory diagram at bearing 2; (i) Poincare map at bearing 2; (j) Frequency spectrum at bearing 2 
(a)
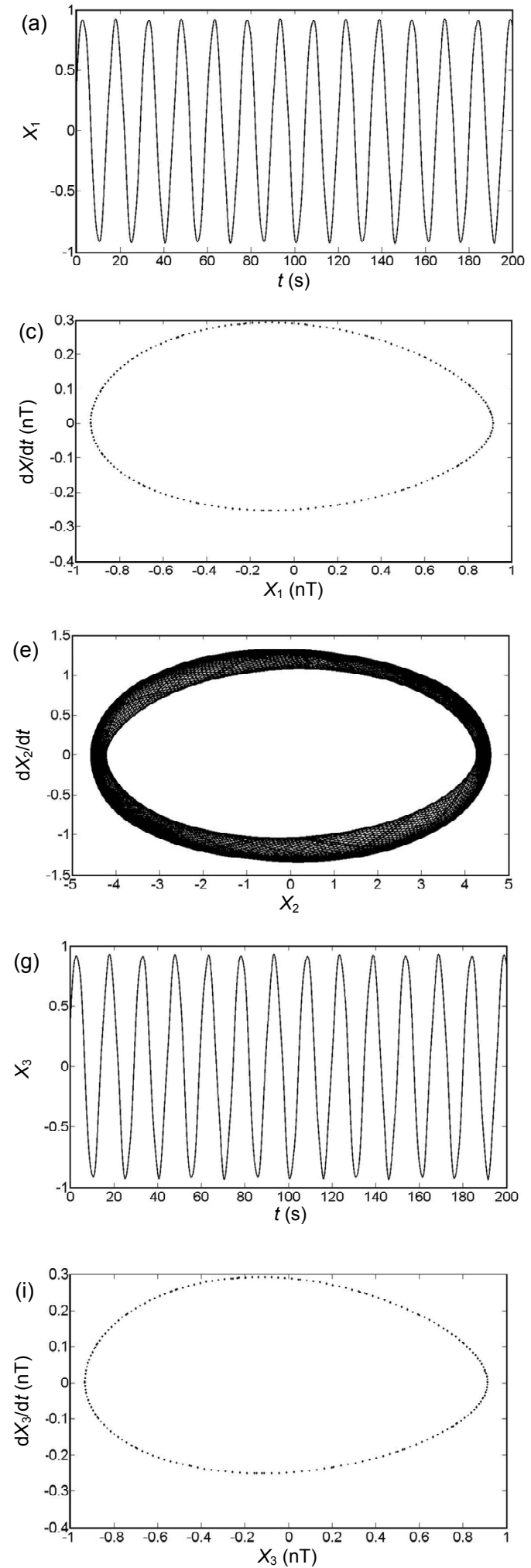
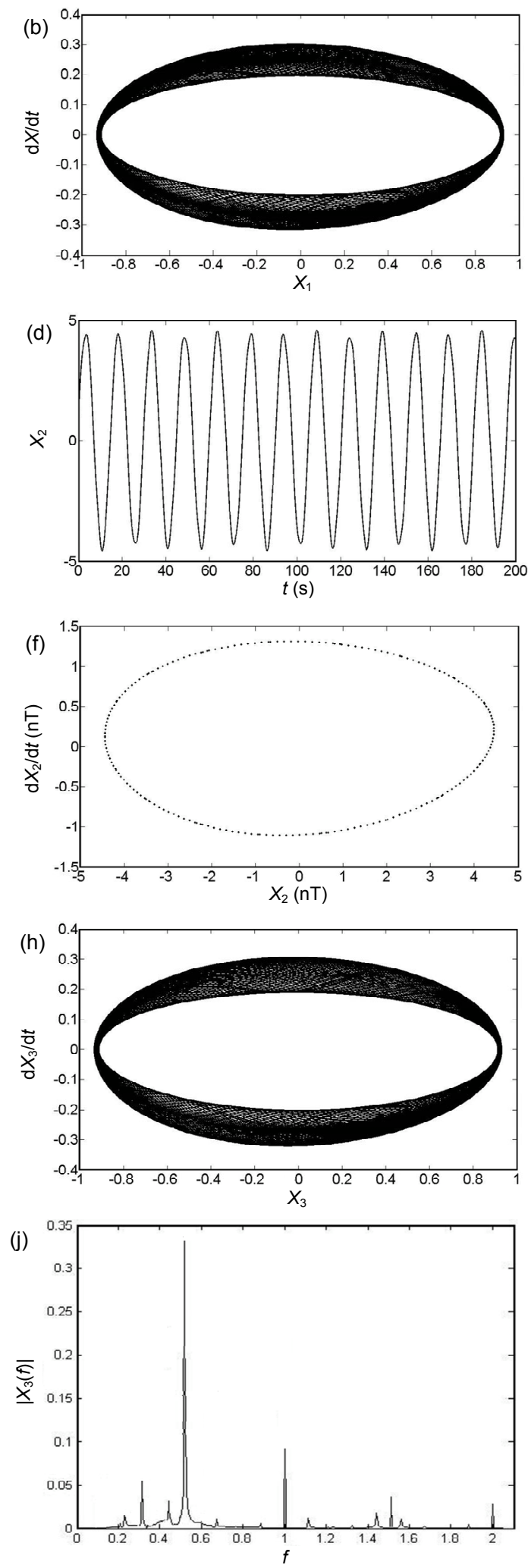

Fig. 8 Numerical analysis results at $\Omega=1400 \mathrm{rad} / \mathrm{s}$

(a) Time-history diagram at bearing 1; (b) Trajectory diagram at bearing 1; (c) Poincare map at bearing 1; (d) Time-history diagram at the disk; (e) Trajectory diagram at the disk; (f) Poincare map at the disk; (g) Time-history diagram at bearing 2; (h) Trajectory diagram at bearing 2; (i) Poincare map at bearing 2; (j) Frequency spectrum at bearing 2 
happens at $900 \mathrm{rad} / \mathrm{s}$ (Fig. 6), the septuple periodic motion happens at $1216 \mathrm{rad} / \mathrm{s}$ (Fig. 7), and the quasiperiodic motion occurs at $1400 \mathrm{rad} / \mathrm{s}$ (Fig. 8), which is shown as a whole cycle in the Poincare map and some frequency parts are unable to be commonly divided in the spectrum of the frequency.

\section{Conclusions}

In this paper, a model of a two-disk and two-span rotor/bearing/seal system is created based on the Hamilton principle, which is more accurate and easier for a numerical solution. The nonlinear coupling vibration of the rotor system is investigated by the fourth-order Runge-Kutta method. The figures achieved with various rotational speeds show the complexity of the nonlinear vibration and the bifurcation behavior of the rotor system. The numerical results indicate that the damping reduction and the increase of the seal pressure drop will make the bifurcation of the rotor system happen earlier, while the increase of the stiffness will prevent the bifurcation points from appearing too early and also greatly reduce the amplitude of the system motion. Based on the numerical analysis, it can be concluded that the rotational speed, the nonlinear seal force, the oil-film force, and the stiffness of the coupling have a great effect on the stability of a rotor system.

This study can enhance understanding of the nonlinear dynamics of rotor systems and be helpful in choosing some designing parameters which affect the stability of the rotor systems. Further work will be done to analyze the nonlinear dynamics of the multidisk and multi-span rotor systems.

\section{References}

Al-Nahwi, A.A., Paduano, J.D., Nayfeh, S.A., 2003. Aerodynamic-rotordynamic interaction in axial compression systems-part II: impact of interaction on overall system stability. Journal of Turbomachinery, 125(3): 416-424. [doi:10.1115/1.1576431]

Chang-Jian, C.W., 2010. Non-linear dynamic analysis of dual flexible rotors supported by long journal bearings. Mechanism and Machine Theory, 45(6):844-866. [doi:10. 1016/j.mechmachtheory.2009.11.010]

Chen, Y.S., 2009. A number of nonlinear dynamics problems in the rotating machinery development. CCTAM, Zhengzhou, China. The Chinese Society of Theoretical and Applied Mechanics, Beijing, China (in Chinese).
Cheng, M., Meng, G., Jing, J.P., 2008. Numerical analysis of nonlinear rotor-bearing-seal system. Journal of Shanghai Jiaotong University (Science), 13(4):418-425. [doi:10. 1007/s12204-008-0418-8]

Childs, D.W., 1983. Dynamic analysis of turbulent annular seals based on Hirs lubrication equation. Journal of Lubrication Technology, 105(3):429-436. [doi:10.1115/1. 3254633]

de Castro, H.F., Cavalca, K.L., Nordmann, R., 2008. Whirl and whip instabilities in rotor-bearing system considering a nonlinear force model. Journal of Sound and Vibration, 317(1-2):273-293. [doi:10.1016/j.jsv.2008.02.047]

Ding, Q., Leung, A.Y.T., 2005. Numerical and experimental investigations on flexible multi-bearing rotor dynamics. Journal of Vibration and Acoustics, 127(4):408-415. [doi:10.1115/1.1898336]

Ertas, B.H., Camatti, M., Mariotti, G., 2010. Synchronous response to rotor imbalance using a damped gas bearing. Journal of Engineering for Gas Turbines and Power, 132(3):032501. [doi:10.1115/1.3157097]

Fei, Z.X., Tong, S.G., Wei, C., 2013. Investigation of the dynamic characteristics of a dual rotor system and its start-up simulation based on finite element method. Journal of Zhejiang University-SCIENCE A (Applied Physics \& Engineering), 14(4):268-280. [doi:10.1631/ jzus.A1200298]

Li, Q., Liu, S.L., Pan, X.H., et al., 2012. A new method for studying the $3 \mathrm{D}$ transient flow of misaligned journal bearings in flexible rotor-bearing systems. Journal of Zhejiang University-SCIENCE A (Applied Physics \& Engineering), 13(4):293-310. [doi:10.1631/jzus.A1100228]

Li, W., Yang, Y., Sheng, D.R., et al., 2011a. Nonlinear dynamic analysis of a rotor/bearing/seal systems. Journal of Zhejiang University-SCIENCE A (Applied Physics \& Engineering), 12(1):46-55. [doi:10.1631/jzus.A1000130]

Li, W., Yang, Y., Sheng, D.R., et al., 2011b. A novel nonlinear model of rotor/bearing/seal system and numerical analysis. Mechanism and Machine Theory, 46(5):618631. [doi:10.1016/j.mechmachtheory.2011.01.002]

Luo, T.S., Wang, S.L., Guo, Y.M., 2007. Application of highdimensional dynamic system in rotor stability analysis. Journal of Zhejiang University (Engineering Science), 41(6):959-962 (in Chinese).

Luo, Y.G., Zhang, S.H., Wu, B., et al., 2012. Effects of two cracks in shafts on dynamic characteristics of two-span rotor-bearing system. Applied Mechanics and Materials, 271-272:1270-1274. [doi:10.4028/www.scientific.net/ AMM.271-272.1270]

Muszynska, A., Bently, D.E., 1990. Frequency-swept rotating input perturbation techniques and identification of the fluid force models in rotor/bearing/seal systems and fluid handling machines. Journal of Sound and Vibration, 143(1):103-124. [doi:10.1016/0022-460X(90)90571-G]

Okabe, E.P., Cavalca, K.L., 2009. Rotordynamic analysis of systems with a non-linear model of tilting pad bearings including turbulence effects. Nonlinear Dynamics, 57(4): 
481-495. [doi:10.1007/s11071-008-9378-7]

Půst, L., Kozánek, J., 2007. Evolutive and nonlinear vibrations of rotor on aerodynamic bearings. Nonlinear Dynamics, 50(4):829-840. [doi:10.1007/s11071-007-9228-z]

Rashidi, R., Karami Mohammadi, A., Bakhtiari-Nejad, F., 2010a. Preload effect on nonlinear dynamic behavior of a rigid rotor supported by noncircular gas-lubricated journal bearing systems. Nonlinear Dynamics, 60(3):231253. [doi:10.1007/s11071-009-9592-y]

Rashidi, R., Karami Mohammadi, A., Bakhtiari-Nejad, F., 2010b. Bifurcation and nonlinear dynamic analysis of a rigid rotor supported by two-lobe noncircular gaslubricated journal bearing system. Nonlinear Dynamics, 61(4):783-802. [doi:10.1007/s11071-010-9687-5]

Wang, W.Z., Liu, Y.Z., Meng, G., et al., 2009. Nonlinear analysis of orbital motion of a rotor subject to leakage air flow through an interlocking seal. Journal of Fluids and Structures, 25(5):751-765. [doi:10.1016/j.jfluidstructs. 2008.07.009]

Wu, Q.L., Jing, K., 2008. Study on dynamics characteristic of two-span bearing-rotor system with nonlinear oil film forces. Journal of Liaoning University of Petroleum \& Chemical Technology, 28(2):53-57 (in Chinese). [doi:10. 3969/j.issn.1672-6952.2008.02.014]

Zeng, P., 2004. Finite Element Analysis and Applications. Tsinghua University Press, Beijing (in Chinese).

Zhou, W.J., Wei, X.S., Wei, X.Z., et al., 2014. Numerical analysis of a nonlinear double disc rotor-seal system. Journal of Zhejiang University-SCIENCE A (Applied Physics \& Engineering), 15(1):39-52. [doi:10.1631/jzus. A1300230]

\section{中文整要:}

本文题目：基于 Hamilton 原理的双跨转子系统建模和转子动态特性分析

Modeling a two-span rotor system based on the Hamilton principle and rotor dynamic behavior analysis

研究目的: 研究双盘双跨转子/轴承/汽封系统在非线性油膜力和非线性汽封力共同作用下的动力学特性, 分析了转子转速、密封力、油膜力和联轴器刚度等因素对转子稳定性的影响。

创新要点: 采用 Hamilton 原理和有限元方法建立双盘双跨转子/轴承/气封系统模型, 使得双跨多节点的转 子系统数值求解更加容易。研究分析转子转速、非线性密封力、非线性油膜力和联轴器刚度等 因素对转子稳定性的影响, 为大型转子系统的设计提供理论基础。

研究方法: 采用 Hamilton 原理和有限元方法建立双盘双跨转子/轴承/汽封系统模型 (图 1 和 2)。应用四阶 Runge-Kutta 法进行数值求解, 并采用轴承处、圆盘处的分岔图、时程图、庞加莱映射图、频 率图和相轨迹图等来分析转子系统的动态特性。

重要结论: 1. 通过数值计算分析, 转子的转速、非线性汽封力、非线性油膜力和联轴器的刚度对双跨 转子的稳定性有重要的影响作用。2. 随着转速的上升, 双跨转子系统从最初的稳定运动, 到三倍周期运动, 到准周期运动和多倍周期运动交替出现, 运动特性相比单跨转子系统要 更为复杂。

关键词组: Hamilton 原理; 双盘双跨转子系统; 非线性汽封力; 动态特性 